\section{FRI0036 VALIDATION OF RISK SCORES FOR PREDICTING PROGRESSION IN INDIVIDUALS "AT RISK OF RHEUMATOID ARTHRITIS"}

L. Duquenne ${ }^{1,2}$, J. Nam ${ }^{1,2}$, K. Mankia ${ }^{1,2}$, L. Garcia-Montoya ${ }^{1,2}$, A. DI Matteo ${ }^{1,2}$, P. Emery ${ }^{1,2} .{ }^{1}$ Leeds Biomedical Research Centre - NIHR, Leeds, United Kingdom; ${ }^{2}$ University of Leeds, Leeds Institute of Rheumatic and Musculoskeletal Medicine, Leeds, United Kingdom

Background: Composite scores for risk of progression were described in 2015 in a cohort of 100 anti-cyclic citrullinated peptide (anti-CCP) + individuals at risk of developing Inflammatory Arthritis (IA) (1). The first score, designed for primary care, was based on anti-CCP and rheumatoid factor (RF) titres, small joints tenderness and early morning stiffness (EMS). A second score developed for secondary care added power Doppler presence (PD+) and/or at least one allele positive for the shared epitope (SE+).

Objectives: To validate previous data by scoring risk factors in a new cohort of 394 individuals.

Methods: Individuals at risk of developing IA selected by a positive anti-CCP test and a new musculoskeletal symptom have been followed in a single-centre prospective observational cohort since 2008. The previous risk score was derived from 100 patients. With the same recruitment and follow-up pathways, the next 394 consecutive participants were studied (full data were available for 373 patients for secondary care model). Participants followed for less than 10 weeks without progression were excluded.

Results: Participants from both cohorts were similar in terms of age and sex. Although the mean time to progression is comparable, there were significantly more participants with a high titre anti-CCP test in the 2015 cohort (Table 1).

Table 1. Patients characteristics

\begin{tabular}{lcc}
\hline Score & 2015 & 2020 \\
\hline $\mathrm{N}$ & 100 & 394 \\
Percentage of progression n/N & $50 / 100(50 \%)$ & $82 / 413(19.9 \%)$ \\
Mean of follow-up before progression to IA (Months (SD)) & $15.35(15.27)$ & $13.50(12.62)$ \\
Mean follow-up of non progressors (Months (SD)) & $39.7(15.82)$ & $27.6(19.75)$ \\
Mean follow-up duration: all participants (Months (SD)) & $27.7(19.36)$ & $24.8(19.38)$ \\
High CCP titre & $83 \%$ & $65 \%$ \\
Women & $72 \%$ & $72 \%$ \\
Smoker ever & $72 \%$ & $50 \%$ \\
Age (Mean (SD)) & $51.2(11.9)$ & $50.2(13.474)$ \\
\hline
\end{tabular}

Cox multivariable analysis showed similar Hazard Ratios (HR) of progression in both groups (Table 2) confirming the high predictive value of high CCP/RF titre, early morning stiffness duration, power doppler presence and shared epitope. High risk of progression individuals identified by the secondary score were eight times more likely to develop IA ( $\mathrm{HR}=8.290, \mathrm{Cl}=3.763-18.264, \mathrm{p}<0.001), 50 \%$ of them had progressed at 2 years (Figure 1).

Table 2. Multivariable Cox regression analysis of time to progression to inflammatory arthritis.

\begin{tabular}{|c|c|c|c|c|c|c|}
\hline \multirow[b]{2}{*}{ Primary care model } & \multicolumn{3}{|c|}{$2015(n=98)$} & \multicolumn{3}{|c|}{$2020(n=394)$} \\
\hline & HR & p-value & $\mathrm{Cl}$ & HR & p-value & Cl \\
\hline High anti-CCP or RF titre & 4.86 & 0.031 & $1.16-20.43$ & 4.96 & $<0.001$ & $1.445-3.526$ \\
\hline$E M S \geq 30 \mathrm{~min}$ & 1.86 & 0.039 & $1.03-3.37$ & 2.26 & $<0.001$ & $1.445-3.526$ \\
\hline \multirow[t]{2}{*}{ Small Joints Tenderness } & 1.42 & 0.252 & $0.78-2.57$ & 1.30 & 0.249 & $0.832-2.035$ \\
\hline & \multicolumn{3}{|c|}{$2015(n=98)$} & \multicolumn{3}{|c|}{$2020(n=373)$} \\
\hline Secondary care model & HR & p-value & Cl & HR & p-value & Cl \\
\hline High anti-CCP or RF titre & 3.04 & 0.147 & $0.68-13.6$ & 3.92 & 0.001 & $1.790-8.567$ \\
\hline $\mathrm{EMS} \geq 30 \mathrm{~min}$ & 1.56 & 0.167 & $0.83-2.92$ & 2.10 & 0.002 & $1.314-3.357$ \\
\hline Small Joints Tenderness & 1.54 & 0.178 & $0.82-2.88$ & 1.34 & 0.216 & $0.843-2.135$ \\
\hline PD signal & 1.92 & 0.033 & $1.06-3.50$ & 2.35 & 0.001 & $1.424-3.887$ \\
\hline Shared epitope & 1.57 & 0.272 & $0.70-3.49$ & 2.33 & 0.003 & $1.333-4.059$ \\
\hline
\end{tabular}

Conclusion: These data from a new large cohort confirm the validity previous Leeds Risk Scores for Primary and Secondary care, and the fidelity of the risk factors over time to predict progression.

References:

[1] Rakieh C, Nam JL, Hunt L, Hensor EM, Das S, Bissell LA, et al. Predicting the development of clinical arthritis in anti-CCP positive individuals with non-specific musculoskeletal symptoms: a prospective observational cohort study. Annals of the rheumatic diseases. 2015;74(9):1659-66.

Disclosure of Interests: Laurence Duquenne: None declared, Jacqueline Nam: None declared, Kulveer Mankia: None declared, Leticia Garcia-Montoya: None

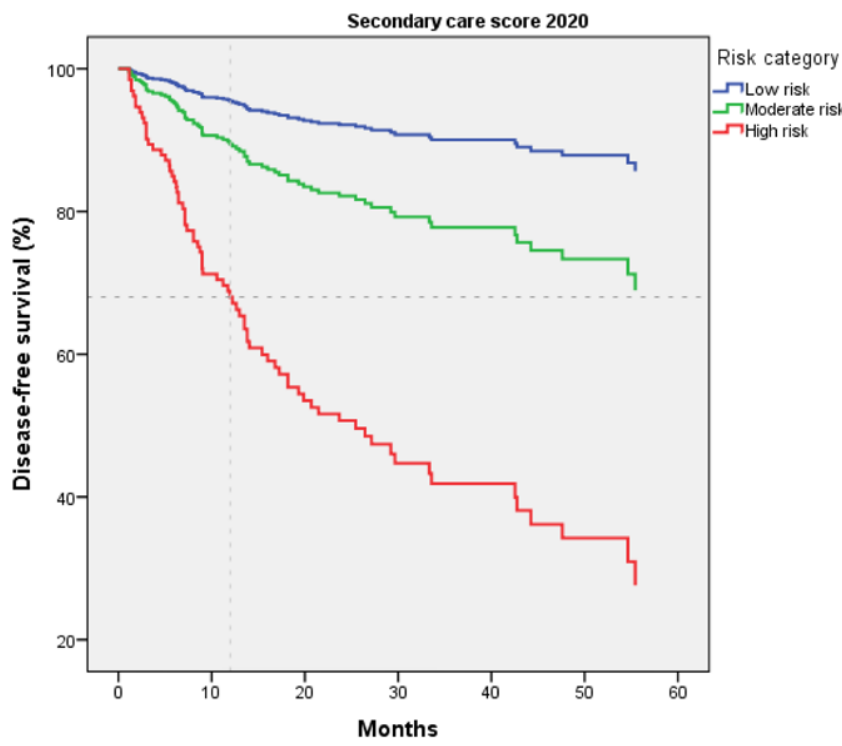

Figure 1. Probability of IA free survival according to categories of risk in the secondary care model.

declared, Andrea Di Matteo Grant/research support from: the publication was conducted while Dr. Di Matteo was an ARTICULUM fellow, Paul Emery Grant/ research support from: AbbVie, Bristol-Myers Squibb, Merck Sharp \& Dohme, Pfizer, Roche (all paid to employer), Consultant of: AbbVie (consultant, clinical trials, advisor), Bristol-Myers Squibb (consultant, clinical trials, advisor), Lilly (clinical trials, advisor), Merck Sharp \& Dohme (consultant, clinical trials, advisor), Novartis (consultant, clinical trials, advisor), Pfizer (consultant, clinical trials, advisor), Roche (consultant, clinical trials, advisor), Samsung (clinica trials, advisor), Sandoz (clinical trials, advisor), UCB (consultant, clinical trials, advisor)

DOI: 10.1136/annrheumdis-2020-eular.4368

\section{\begin{tabular}{|l|l}
\hline FRI0037 ALL-CAUSE MORTALITY IN EARLY RHEUMATOID \\
\hline
\end{tabular} ARTHRITIS PREDICTED BY HEALTH ASSESSMENT QUESTIONNAIRE AT ONE YEAR}

S. Fatima ${ }^{1}$, O. Schieir ${ }^{2}$, M. F. Valois ${ }^{3}$, S. J. Bartlett ${ }^{3}$, L. Bessette ${ }^{4}$, G. Boire ${ }^{5}$ G. Hazlewood ${ }^{6}$, C. Hitchon ${ }^{7}$, E. Keystone ${ }^{2}$, D. Tin ${ }^{8}$, C. Thorne ${ }^{9}$, V. Bykerk ${ }^{10}$, J. Pope ${ }^{1}$ on behalf of CATCH Investigators. ${ }^{1}$ Western University, London, Canada; ${ }^{2}$ University of Toronto, Toronto, Canada; ${ }^{3} \mathrm{Mc}$ Gill University, Montreal, Canada; ${ }^{4}$ Université de Laval, Quebec, Canada; ${ }^{5}$ Université de Sherbrooke, Sherbrooke, Canada; ${ }^{6}$ University of Calgary, Calgary, Canada; ${ }^{7}$ University of Manitoba, Winnipeg, Canada; ${ }^{8}$ Southlake Regional Health Centre, Newmarket, Canada; ${ }^{9}$ Southlake Regional Health Center, Newmarket, Canada; ${ }^{10} \mathrm{Hospital}$ for Special Surgery; Weill Cornell Medical College, New York, United States of America

Background: Patients with RA are at greater risk of mortality than the general population. Higher HAQ disability has been associated with hospitalizations and mortality in established RA; whether HAQ disability predicts mortality in early RA (ERA) is unknown.

Objectives: The objective of this study is to analyze how well the HAQ can predict future mortality in patients with early RA.

Methods: Data were from adult early RA patients (symptoms $<1$ year) enrolled in the Canadian Early Arthritis Cohort (CATCH) between 2007 and 2017; who initiated treatment with 1 or more DMARDs and had completed HAQ data at baseline and 1 year. Descriptive statistics, t-tests and chi-square tests were used to summarize and compare baseline patient characteristics including sociodemographic variables, RA characteristics and comorbidities amongst deceased and non-deceased patients. Discrete-time proportional hazards models were used to estimate crude and multi-adjusted associations between HAQ at baseline and 1 year, respectively, with all-cause mortality in each year of follow up.

Results: This study included 1724 patients with early RA; mean age was 55 years and $72 \%$ were female. In 10 years of follow up, 62 deaths $(2.4 \%)$ occurred. Deceased patients had higher HAQ scores and DAS28 scores at baseline and at 1 year versus the non-deceased group. Age, male sex, lower education, smoking, more comorbidities, higher baseline disease activity and steroid use were associated with mortality in unadjusted survival models (Table 1). Contrary to $\mathrm{HAQ}$ at baseline, the association between all-cause mortality and $\mathrm{HAQ}$ at 1 yea 
remained significant even after adjusting for age, gender, comorbidities, disease activity, smoking, education, seropositivity, symptom duration and steroid use in adjusted survival models (Table 2 ).

Table 1. Unadjusted survival model: Association of each variable with all-cause mortality

\begin{tabular}{lcc}
\hline Baseline Variable & $\begin{array}{c}\text { Unadjusted } \\
\text { Hazard OR }\end{array}$ & $95 \% \mathrm{Cl}$ \\
\hline Socio-Demographic & & \\
Age (years) & 1.10 & $1.07-1.13$ \\
Female & 0.37 & $0.22-0.62$ \\
Caucasian (white or European) & 1.01 & $0.46-2.24$ \\
Aboriginal & 1.71 & $0.61-4.76$ \\
Education > high school degree & 0.48 & $0.28-0.82$ \\
Current Smoker & 1.81 & $1.01-3.24$ \\
Rheumatic Disease Comorbidity Index (0-9) & 1.60 & $1.36-1.87$ \\
RA Characteristics & & \\
Symptom duration (months) & 0.99 & $0.91-1.08$ \\
Seropositivity in first year & 1.11 & $0.55-2.23$ \\
DAS28 ESR or CRP if ESR is missing & 1.26 & $1.06-1.51$ \\
Oral Steroid use & 1.75 & $1.03-2.98$ \\
\hline
\end{tabular}

Table 2. Multivariable discrete-time survival models: HAQ baseline vs 1 year

\begin{tabular}{cccccc}
\hline Model & Model 1: & Model 2: & Model 3: & Model 4: & Model 5: \\
& Crude & Adjusted for age & Adjusted for & Adjusted for & Adjusted \\
(Time + & + sex & Model 2 + & Model 3 + edu- & for Model 3 \\
HAQ-DI) & & DAS28 + & cation, smoking, & + smoking, \\
& & RDCl & seropositivity, & symptom \\
& & & symptom & duration \\
& & & duration and oral & only \\
& & & & steroids use &
\end{tabular}

\begin{tabular}{lcccccccccc}
\hline HAQ-DI & 1.46 & 1.02 & 1.37 & 0.96 & 1.25 & 0.81 & 1.32 & 0.85 & 1.30 & 0.84 \\
$\begin{array}{l}(0-3) \text { (at } \\
\text { baseline) }\end{array}$ & & -2.09 & & -1.95 & & -1.94 & & -2.04 & - \\
HAQ-DI & 2.58 & 1.78 & 2.40 & 1.63 & 1.75 & 1.10 & 1.87 & 1.16 & 1.73 & 1.09 \\
$\begin{array}{l}(0-3) \text { (at 1 } \\
\text { year) }\end{array}$ & & -3.72 & & -3.52 & & -2.77 & & -3.02 & - \\
\hline
\end{tabular}

*Hazard OR, 95\% Cl

HAQ-DI: (Health Assessment Questionnaire Disability Index); RDCI: Rheumatic Disease Comorbidity Index; DAS28: Disease Activity Score

Conclusion: Higher $\mathrm{HAQ}$ at 1 year was significantly associated with all-cause mortality in a large early RA cohort suggesting that poorer disease control and function in the first year of RA contributes to higher mortality.

Disclosure of Interests: Safoora Fatima: None declared, Orit Schieir: None declared, Marie-France Valois: None declared, Susan J. Bartlett Consultant of: Pfizer, UCB, Lilly, Novartis, Merck, Janssen, Abbvie, Speakers bureau: Pfizer, UCB, Lilly, Novartis, Merck, Janssen, Abbvie, Louis Bessette Grant/research support from: AbbVie, Amgen, Bristol-Myers Squibb, Celgene, Eli Lilly, Janssen, Merck, Novartis, Pfizer, Roche, Sanofi, UCB Pharma, Consultant of: AbbVie, Amgen, Bristol-Myers Squibb, Celgene, Eli Lilly, Janssen, Merck, Novartis, Pfizer, Roche, Sanofi, UCB Pharma, Speakers bureau: AbbVie, Amgen, Bristol-Myers Squibb, Celgene, Eli Lilly, Janssen, Merck, Novartis, Pfizer, Sanofi, Gilles Boire Grant/research support from: Merck Canada (Registry of biologices, Improvement of comorbidity surveillance)

Amgen Canada (CATCH, clinical nurse)

Abbvie (CATCH, clinical nurse)

Pfizer (CATCH, Registry of biologics, Clinical nurse)

Hoffman-LaRoche (CATCH)

UCB Canada (CATCH, Clinical nurse)

BMS (CATCH, Clinical nurse, Observational Study Protocol IM101664. SEROPOSITIVITY IN A LARGE CANADIAN OBSERVATIONAL COHORT) Janssen (CATCH)

Celgene (Clinical nurse)

Eli Lilly (Registry of biologics, Clinical nurse), Consultant of: Eli Lilly, Janssen, Novartis, Pfizer, Speakers bureau: Merck, BMS, Pfizer, Glen Hazlewood: None declared, Carol Hitchon Grant/research support from: UCB Canada; Pfizer Canada, Edward Keystone Grant/research support from: AbbVie, Amgen, Bristol-Myers Squibb, F. Hoffmann-La Roche Inc, Gilead, Janssen Inc, Lilly Pharmaceuticals, Pfizer Pharmaceuticals, Sanofi-Aventis, Consultant of: AbbVie, Amgen, AstraZeneca Pharma, Biotest, Bristol-Myers Squibb Company, Celltrion,
Crescendo Bioscience, F. Hoffmann-La Roche Inc, Genentech Inc, Gilead, Janssen Inc, Lilly

Pharmaceuticals, Merck, Pfizer Pharmaceuticals, Sandoz, UCB., Speakers bureau: Amgen, AbbVie, Bristol-Myers Squibb Canada, F. Hoffmann-La Roche Inc., Janssen Inc., Merck, Pfizer Pharmaceuticals, Sanofi Genzyme, UCB Diane Tin: None declared, Carter Thorne Consultant of: Abbvie, Centocor, Janssen, Lilly, Medexus/Medac, Pfizer, Speakers bureau: Medexus/Medac Vivian Bykerk: None declared, Janet Pope Grant/research support from: AbbVie, Bristol-Myers Squibb, Eli Lilly \& Company, Merck, Roche, Seattle Genetics, UCB, Consultant of: AbbVie, Actelion, Amgen, Bayer, Boehringer Ingelheim, Bristol-Myers Squibb, Eicos Sciences, Eli Lilly \& Company, Emerald, Gilead Sciences, Inc., Janssen, Merck, Novartis, Pfizer, Roche, Sandoz, Sanofi, UCB, Speakers bureau: UCB

DOI: 10.1136/annrheumdis-2020-eular.2508

\begin{tabular}{|l|l}
\hline FRI0038 & THE RELATIONSHIP BETWEEN ABATACEPT \\
EXPOSURE AND EFFICACY MEASURES IN EARLY \\
MTX-NAIVE ANTI-CITRULLINATED PROTEIN \\
ANTIBODY-POSITIVE PATIENTS WITH RA DURING \\
THE DE-ESCALATION PERIOD OF A PHASE IIIB \\
STUDY
\end{tabular}

Y. Gandhi $^{1}$, S. Connolly ${ }^{1}$, K. H. G. Huang ${ }^{1}$, R. Wong ${ }^{1}$, S. Chilewski ${ }^{1}$, B. Murthy ${ }^{1}$. ${ }^{1}$ Bristol-Myers Squibb, Princeton, United States of America

Background: Although EULAR/ACR guidelines suggest tapering biologic treatment for RA following sustained remission in patients (pts), specific de-escalation (DE) regimens are not defined. The Phase IIlb Assessing Very Early Rheumatoid arthritis Treatment (AVERT)-2 trial (NCT02504268) is evaluating SC abatacept (ABA) + MTX versus ABA placebo (PBO) + MTX in Anti-Citrullinated Protein Antibody (ACPA)-positive pts with early (ACR/EULAR 2010 criteria; disease duration $\leq 6 \mathrm{mths}$ ), active RA (SDAI >11). AVERT-2 was designed to investigate achievement of SDAI remission and a clinically meaningful dose $D E$ strategy among pts in sustained remission who completed induction with $A B A+M T X$. In moderately to severely active RA and JIA patients, a relationship between ABA Cmin and efficacy was observed. Therefore, this analysis in very early RA patients, reports on the pharmacokinetics (PK) and immunogenicity of $A B A$ and the maintenance of remission during the DE period of AVERT-2.

Objectives: To assess the relationship between changes in ABA exposure and the maintenance of remission and the effect of immunogenicity on exposure during the DE period of AVERT-2.

Methods: Pts received blinded SC ABA (125 mg once wkly [QW]) + MTX or ABA $\mathrm{PBO}+\mathrm{MTX}$ induction treatment for 56 wks. Pts who completed induction with $\mathrm{ABA}+\mathrm{MTX}$ and had sustained SDAl remission ( $\leq 3.3$ at Wks 40 and 52 ) were re-randomized 1:1:1 to ABA QW + MTX for 48 wks (Arm C), ABA every other wk $(E O W)+M T X$ for 24 wks followed by ABA PBO + MTX for 24 wks (Arm D), or ABA QW + MTX PBO for 48 wks (Arm E) in the DE period. ABA trough (Cmin) and anti-drug antibody (ADA) samples were collected in all subjects during the DE period. Serum ABA concentrations and ADA were measured using a validated enzyme immunoassay method and an electrochemiluminescence assay, respectively. Efficacy endpoints included change from DE Day 1 in SDAI score, HAQ-DI score, Physician's Global Assessment (PhGA), and tender (TJC) and swollen (SJC) joint counts. The relationship between ABA Cmin and efficacy endpoints were assessed. Additionally, the impact of immunogenicity on ABA Cmin was explored.

Results: Mean ABA Cmin values remained stable throughout the DE period for subjects in Arms C and E. ABA Cmin values decreased by $~ 50 \%$ in subjects in Arm $D$ for the first 24 weeks from the start of DE and were $\sim 0$ for weeks 24-48 consistent with the change in the frequency of $A B A$ dosing from EOW to $A B A$ withdrawal (Figure 1 top).

The incidence of immunogenicity appeared to increase upon withdrawal of ABA in Arm D. ADA formation did not appear to affect ABA Cmin, as ABA Cmin remained consistent between pts with and without ADA.

Upon withdrawal of ABA in Arm D, there appeared to be an increase in the mean change from baseline (Day 1 of DE) in SDAl over time, which followed a similar time course as the washout of $\mathrm{ABA}$ (Figure 1 bottom). Similar results were observed for other efficacy endpoints such as HAQ-DI, PhGA, TJC, and SJC. Conclusion: The PK data in these early onset, MTX-naive, ACPA+ RA pts correlated well with the maintenance of remission in Arms $A$ and $E$. Tapering of $A B A$ from EOW to MTX only in Arm D results in a corresponding decrease in ABA $\mathrm{Cmin}$, an increase in positive antibody response, and loss of remission. References:

[1] Emery et. al. ACR [Abstract L11]. Nov. 2019. Atlanta GA USA

[2] Li et. al. J Clin Pharmacol. Vol 59(2). Feb 2019.

Disclosure of Interests: Yash Gandhi Shareholder of: Bristol-Myers Squibb, Employee of: Bristol-Myers Squibb, Sean Connolly Shareholder of: Bristol-Myers 